\title{
УДК 78.036"19"
}

\section{Е. Б. КостюК}

\section{Массовая музыка как явление культуры XX в.}

В статье рассматривается массовая музыка как явление социально-художественное в культуре XX в. Ocвещаются вопросы социально-культурных, технологических факторов, способствовавших развитию музыки как явления массового в XX в. Осмысливается феномен массовой музыки в сопоставлении с элитарным, академическим направлением в музыке, исследуются особенности социального заказчика. Оценка массовой музыки как художественного и социального явления приводит к выводу, что развлекательность как основная ее функция имеет целый ряд особенностей на протяжении столетия: от подчеркнутой релаксационной танцевальности в эпоху модерна к концепту игры, эпатажа, театральности в эпоху постмодерна.

Анализируются особенности массовой музыки как «товара эпохи потребления» в условиях современного художественного рынка, который имеет «жизненный цикл», и в условиях конкуренции задачей создателей ее становится не воплощение ценностей и смыслов, а их использование с целью долговременного извлечения прибыли. В статье также исследуются аспекты музыкально-художественной специфики рассматриваемого направления.

Ключевые слова: массовая музыка, массовая культура, художественный рынок, джаз, рок-музыка, элитарное искусство

\section{Ekaterina B. Kostiuk}

\section{Mass music as a cultural phenomenon of the $\mathrm{XX}$ century}

The article considers mass music as a socio-artistic phenomenon in the culture of the XX century. The article covers the issues of socio-cultural and technological factors that contributed to the development of music as a mass phenomenon in the XX century. The phenomenon of mass music is interpreted in comparison with the elite, academic direction in music, and the features of the social customer are studied. Evaluation of mass music as an artistic and social phenomenon leads to the conclusion that entertainment, as its main function, has a number of features over the course of the century: from the emphasized relaxation dance in the modern era to the concept of play, outrage, and theatricality in the postmodern era.

Analyzes the characteristics of mass music as «product of the era of consumption» in the modern art market, which has a «life cycle», and in the conditions of the competition task creators, it is not the embodiment of values and meanings, and their use for the long-term profit. The article also explores the aspects of musical and artistic specificity of the considered direction.

Keywords: mass music, mass culture, art market, jazz, rock music, elite art DOI 10.30725/2619-0303-2020-3-63-67

Музыка всегда была важным фактором бытовой и духовной культуры разных стран и народов. С древнейших времен она выполняла функции коммуникативного, культового, релаксационного, социального характера. Ее способность воздействовать на духовном и физическом уровне на человека стала предметом внимания от древнегреческих и китайских философов до ученых настоящего времени. Особенно важно отметить, что влияние это оценивалось как с позитивной точки зрения, так и с долей опасения в полезности слушания любой музыки, особенностей формирования выразительных возможностей музыки, с этой точки зрения в том числе. Представляется важным в рамках данной работы осмыслить характерные черты массовой музыки как социально-художественного явления культуры XX в. в этом контексте.
Массовая музыка как явление культуры $\mathrm{XX}$ в. является, безусловно, продолжением художественно-социальной специфики музыки «третьего пласта», о которой подробно было написано в исследовании отечественного ученого В. Д. Конен [1]. В этом плане представляется важным отметить, что музыка «третьего пласта» формировалась изначально как развлекательная, украшающая досуг, основным социальным заказчиком которой был городской средний класс (ремесленники, торговцы и т. д.).

Развлекательность искусства - это его важнейшая социально-культурная роль, она позволяет в массовом и индивидуальном контекстах «снять» напряжение, изменить настроение с агрессии на позитивное. Музыка, прежде всего, благодаря ритму, его способности на физиологическом уровне воздействовать на массу людей 
и на каждого человека в отдельности в разных культурах с древних времен использовалась как средство воздействия на эмоциональность человека, племени, сообщества. Об этом свидетельствуют исследования западных и отечественных ученых. Поэтому в культурах всех стран есть музыка развлекательного и расслабляющего характера.

Художественные особенности музыки данного назначения определялись особенностями «языка культуры» [2] в рамках, которой они формировались: актуальность темы для максимально большего числа слушателей без претензий на философское углубленное размышление (любовь, дружба и т. п.); песенность, позволяющая легко запомнить и передать другим произведение; танцевальность, упрощенность до физиологичности ритма, который позволял «втягивать» в слушание, расслаблял участников, привносил удовольствие; модные музыкальные инструменты эпохи, например, лютня в эпоху Возрождения, фортепиано, гитара в XIX в. и т. п.; харизматичные исполнители, успех которых далеко не всегда определялся исключительно хорошим голосом или виртуозным владением инструментом; стремление к синтезу с другими видами искусства.

По нашему мнению, ограничение в распространении музыки данного направления было связано с несколькими аспектами: носители не воспринимались как социально-значимые ни для развития данного вида искусства (непрофессионалы), ни для социума - представители среднего или низшего класса; устная форма существования большинства произведений, которые интерпретировались при следующем воспроизведении автором или его последователями, поэтому до XX в. вряд ли можно характеризовать музыку «третьего пласта» термином «массовая». Главными социальными заказчиками на протяжении столетий, определяющими направление развития культуры и искусства, были духовенство и аристократия - элита общества, культивировавшая духовно-эстетическую функцию музыки, элитарное искусство, профессионализм. Именно они пестовали творцов, «элитарность выражает свою сущность через культ лучшей личности» [3, с. 8], смыслы искусства, его духовно-нравственное, эстетическое наполнение, связанное в европейской культуре с высотой христианских идей. Однако разрушение этих идеалов на рубеже XIX-XX в. открыло еще одно основание для активизации именно развлекательных форм искусства, музыки, когда все превращается в развлечение, игру, и даже «святое» (например, любовь) лишь повод для того, чтобы заработать. «Кумирами массовой культуры заболтаны... святые заповеди и сокровенные тайны, необходимые для оправдания смысла жизни...» [4], а также, конечно, и глубинного истинного смысла искусства. Безусловно, искусство «третьего пласта» с элитарным находится в постоянной диалектической взаимосвязи, в том числе и в музыке. Культивирование элитами определенных музыкальных жанров, форм их восприятия на протяжении столетий становилось предметом для подражания в городских низах, но, с другой стороны, народная музыка, городской фольклор «питал» и творчество профессионалов. Однако музыка «третьего пласта» не становилась до XX в. ведущим направлением в культуре, только побочной ветвью, прежде всего, на ниве средств выразительности и жанров.

Массовой музыка «третьего пласта» стала в XX в. Как социально-культурное и художественное явление, она приобрела столь большое значение в жизни общества и человека, обогатилась новыми средствами выразительности, во многом благодаря распространению и укоренению в культуре XX в. феномена массового общества, массового искусства [5; 6; 7], «массовое искусство заполнило жизнь человека» [8], которое обуславливалось как ростом городов, так и стремительным развитием средств технического прогресса.

Значение технического прогресса рассматривалось в трудах отечественных и зарубежных ученых, философов. Роль техники, машины в жизни человека при этом осмысливалась как с положительной точки зрения - возможность преодоления ограниченности физических возможностей человека, расширения коммуникативности, круга средств выразительности в искусстве и т. д., так и с отрицательной - усиление технологизации как основы для деградации человека (интеллектуальной, гуманистической и т. п.), уничтожения человечества, технологически целенаправленно или случайно. Для музыки как вида искусства, всегда зависящего от времени, поскольку произведение музыки «живет» во всей полноте пока звучит, изобретение звукозаписывающей и звукотранслирующей техники стало возможностью «остановить» время и передать «полноту» звучания многократно. В этом плане развитие технологий стало позитивным фактором для развития музыки как вида искусства и особенно развлекательной, потому что массовость как характеристику музыки мы можем относить к области социологической и культурной по большей мере.

Итак, в XX в. массовая музыка как явление культуры отображает интересы основного социального заказчика - городского среднего 
класса. Проблеме развития массовой культуры, искусства уделили свое внимание отечественные и западные ученые, философы, отметив, что огромное значение для их формирования и развития имел технический прогресс, и открытия в сфере науки и техники. Как уже отмечалось ранее, именно появление технических средств сделало возможным массовое приобщение к музыке человечества, а также обусловило появление киноискусства, Интернета и т. п. Однако необходимо отметить, что в культуре XX в. при возможности массового приобщения к музыке любого направления только развлекательная музыка в общественном сознании и в культурном дискурсе получила статус массовой. Классическая музыка и фольклор, эти два не менее значимых в истории музыки «пласта» (термин В. Д. Конен), не востребованы в сопоставимых с музыкой «третьего пласта» масштабах. Представляется, что это обусловлено тем, что массовому социальному заказчику (слушателю) во-первых, сложен музыкальный язык, особенно академической музыки XX в. для восприятия; во-вторых, он далек от реальных форм современной бытовой жизни (фольклор); в-третьих, интересы современного слышателя-потребителя ${ }^{1}$ постоянно нацелены в условиях воспитавшей уже его культуры массового потребления на новое, обновленное, а это возможно только в рамках развлекательной музыки, всегда опирающейся на упрощенно стереотипно-действующие ритмоформулы и интонации. Настоящее произведение искусства требует от создателя глубины мысли, чувств и времени на то, чтобы оно появилось.

Для направлений и жанров массовой музыки XX в. свойственна «кратковременность жизненного цикла», что вполне соответствует сущности массовой культуры, массового производства как ее неотъемлемой части и характеристики. В данном случае представляется уместным использовать терминологию менеджмента и маркетинга, поскольку характеристикой данного явления становится ее коммерческая актуальность. Именно массовая музыка является основным «ходовым» товаром в сфере артбизнеса, самые продаваемые музыкальные шлягеры - это эстрадные песни, к которым применимы все законы эпохи «культуры потребления»: легко потребляемое, доступное (по смыслу и формату, формам приобщения), постоянно обновляемое или совсем новое. В этом плане жанры и направления массовой музыки XX в. - яркий тому пример.

Первая половина XX в., культура эпохи модерна связана с появлением массово востребо-

${ }^{1}$ Слышатель - значит воспринимающий музыку только как фон, развлечение. ванного рэгтайма, джаза, мюзикла и т. п. Общей характеристикой этих музыкальных явлений может стать танцевальность ритма, т. е. нацеленность на развлекательность, пробуждающая исключительно радостные эмоции, актуальные в условиях сложной социально-политической, экономической обстановки XX в. - революции, войны, экономические кризисы. Возрастание количества населения в городах, как верно отмечает в своей работе Н. А. Хренов, вызвало потребность в массовых формах искусства [9] как факторе снижения агрессии в обществе, решении проблемы дефицита общения, а, следовательно, компенсации ощущения одиночества в многомиллионном городе.

Во второй половине XX в. нацеленность на развлекательность сохраняется, однако обогащается новыми характеристиками, свойственными в целом культуре постмодерна: игра (глэм-рок и т. п.), эпатаж (хеви-металл, щок-рок и т. п.), театральность (диско, панк, хип-хоп и т. п.). Особым проявлением массового в культуре XX в. становится рок-музыка. Как представляется, массовость распространения в условиях западноевропейской, американской культур рок-музыки была связанна не только с новыми идеями, но также и экономически обусловлена. Новизна, необычность рок-культуры сразу вызвали огромный интерес как новый товар, появившийся на рынке. Продвижение «роктовара» в условиях массового производства было опосредованно техническими возможностями его распространения и обуславливалось всеми средствами и способами, которые применяются в промышленном производстве, для того чтобы «жизненный цикл» товара был как можно дольше: эпатаж, рекламные технологии, новая песня - новый концертный тур, использование в кинопроизведениях и т. п.

В СССР увлечение рок-н-роллом, а затем рок-музыкой с конца 1950-х до 1980-х гг. носило первоначально гедонистический и идеологический характер. Однако известно, что сначала джаз, а потом и рок, например, нелегальные записи рок-групп «Кино», «ДДТ» и т. д., стали «востребованным товаром» советского черного рынка. Не менее интересной была судьба авторской песни как явления, безусловно, художественного и социально-культурно значимого. Песни бардов, так же как и рок-андеграунда, распространялись нелегально, но большинство граждан СССР считало обязательным иметь в доме записи В. Высоцкого, А. Городницкого, группы «Битлз», группы «Аквариум» и т. п., что порождало, конечно, теневой коммерческий рынок этого «товара». В 1990-х гг., когда страна «взяла курс на капитализм», и рок-движение, 
и движение бардов, вовлеченное в тотальную коммерциализацию («чес концертов»), «прекратили» развитие этих музыкальных направлений как музыкально-художественных явлений, о чем свидетельствуют интервью музыкантов, зато стали весомой частью художественного рынка этого периода в постсоветской России. «Служенье муз не терпит суеты» (А. С. Пушкин). К сожалению, трудно сегодня оценить значение и популярность в обществе того или иного направления музыки в 1990-х - начале 2000-х гг., поскольку советская наука в этот период находилась в серьезном кризисе, и те значимые научные исследования музыкальных предпочтений, которые были сделаны фактически на излете советской эпохи в этой сфере [10], представляют несомненный важный материал для продолжения научных изысканий в этой области, для оценки роли элитарной (академической) и эстрадной (развлекательной) музыки в жизни современного российского общества разных социальных категорий.

Художественно-выразительная специфика массовой музыки XX в., начиная с рэгтайма до современных эстрадных шлягеров, через весь век основывается, прежде всего, на подчеркнуто упрощенном танцевальном ритме с акцентом на слабую долю. При этом необходимо отметить, что при всем внимании к неевропейским культурам в XX в. - индийской, китайской и др. - определяющим в ритме и гармонии стало влияние африканской музыкальной культуры, которая в синтезе с европейским мелодико-гармоническим мышлением дала наиболее яркий результат - джаз. Начиная именно с джаза формируется специфика музыкального языка всей массовой музыки XX в. при всех особенностях национальных культур в той или иной стране. Возникновение новых музыкальных инструментов - электрогитары, синтезатора, ударной установки и т. п., а также звукотрансформацию и звукоусиление - так же можно отнести к средствам не только воздействия на слушателя, но и художественной выразительности. К ним следует добавить интерактивность, предполагающую ответную реакцию слушателей как сотворчество; основные темы и образы - любовь, ненависть, дружба в разных интерпретациях; развлекательность как основную функцию.

Массовая музыка XX в. при всем разнообразии жанров и стилей, которые в тот или иной период становились популярными у масс слушателей, сохраняет при этом главную свою особенность: это товар, а значит, у него есть «жизненный цикл», поэтому главной задачей его создателей становится не воплощение ценностей и смыслов, а их использование с целью максимально долговременного извлечения прибыли.

Таким образом, массовая музыка XX в. как явление социально-культурное отображает потребности основного социального заказчика в культуре XX в. - городского среднего класса, при этом развитие ее было опосредовано техническими достижениями (массовая доступность), модой, например, на джаз, рок-н-ролл и т. д., потребительским спросом на новое, развлекательное, «легкоусвояемое», характерными качествами «товара» «эпохи потребления», девальвацией социально-культурной роли элитарного искусства. Художественные особенности массовой музыки XX в. характеризуются подчеркнутой танцевальностью ритма с акцентом на слабую долю, доминантой синтеза европейского и неевропейского (африканского) музыкального мышления, переходом от ярко выраженного в первой половине XX в. мелодизма, вокальности в произведении к ритмическому микроматизму (рэп и т. п.)

\section{Список литературы}

1. Конен В. Д. Третий пласт: новые массовые жанры В музыке XX века. Москва: Музыка, 1994. 160 с.

2. Махлина С. Т. Язык искусства в контексте культуры. Санкт-Петербург: С.-Петерб. гос. акад. культуры, 1995. 217 с.

3. Комиссаренко С. С. Духовно-интеллектуальная элита как феномен отечественной культуры: автореф. дис. ... д-ра культурологии / С.-Петерб. гуманитар. ун-т профсоюзов. Санкт-Петербург, 2005. 43 с.

4. Марков А. Н. Цивилизация эпохи постмодерна: симптомы духовного кризиса: некоторые итоги XIX междунар. Лихачевских чтений // Культура культуры: электрон. журн. 2019. № 4. URL: http://www.cult-cult.ru/postmoderncivilization-symptoms-of-spiritual-crisis/ (дата обращения: 23.03.2020).

5. Ортега-и-Гассет. Дегуманизация искусства // ЛитМир: электрон. б-ка. URL: https://www.litmir.me/ $\mathrm{br} / ? \mathrm{~b}=81219 \& \mathrm{p}=1$ (дата обращения: 23.03.2020).

6. Костина А. В. Массовая культура как феномен постиндустриального общества: автореф. дис. ... д-ра филос. наук: 24.00.01. Москва, 2003. 35 с.

7. Соколов Е. Г. Аналитика масскульта. СанктПетербург: С.-Петерб. филос. о-во, 2001. 279 с.

8. Махлина С. Т. Массовое и элитарное искусство // Семиотика культуры и искусства: словарь-справочник: в 2 кн. 2-е изд., испр. и доп. Санкт-Петербург: Композитор, 2003. Кн. 2. С. 3-18.

9. Хренов Н. А. Публика в истории культуры: феномен публики в ракурсе психологии масс. Москва: Аграф, 2007. 495 c.

10. Молзинский В. В. Проблемы изучения современных тенденций музыкального развития молодежи: автореф. дис. ... канд. искусствоведения: 17.00.02 / Ле- 


\section{Массовая музыка как явление культуры XX в.}

нингр. гос. консерватория им. Н. А. Римского-Корсакова. Ленинград, 1986. 16 с.

\section{References}

1. Konen V. D. The third layer: new mass genres in the music of the XX century. Moscow: Muzyka, 1994.160 (in Russ.).

2. Makhlina S. T. Language of art in the context of culture. Saint-Petersburg: Saint-Petersburg State Acad. of Culture, 1995. 217 (in Russ.).

3. Komissarenko S. S. Spiritual and intellectual elite as a phenomenon of national culture: abstr. dis. on competition of sci. degree PhD in culturology / Saint-Petersburg Univ. of the Humanities and Social Science. Saint-Petersburg, 2005.43 (in Russ.).

4. Markov A. N. Civilization of the postmodern era: symptoms of a spiritual crisis: some results of the XIX inter. Likhachev readings. Culture of culture: electronic j. 2019. 4. URL: http://www.cult-cult.ru/postmodern-civilization-symptomsof-spiritual-crisis/ (accessed: Mar. 23.2020) (in Russ.).
5. Ortega y Gasset. Dehumanization of art. LitMir: electronic libr. URL: https://www.litmir.me/br/?b=81219\& $\mathrm{p}=1$ (accessed: Mar. 23.2020) (in Russ.).

6. Kostina A. V. Mass culture as a phenomenon of postindustrial society: abstr. dis. on competition of sci. degree $\mathrm{PhD}$ in philosophy: 24.00.01. Moscow, 2003. 35 (in Russ.).

7. Sokolov E. G. Analytics of mass culture. SaintPetersburg: Saint-Petersburg Philosophical Soc., 2001. 279 (in Russ.).

8. Makhlina S. T. Mass and elite art. Semiotics of culture and art: dict.-ref. bk: in 2 bks. 2nd ed., rev. and add. SaintPetersburg: Kompoziter, 2003. Bk. 2. 3-18 (in Russ.).

9. Khrenov N. A. The public in the history of culture: the phenomenon of the publ. in the perspective of the psychology of the masses. Moscow: Agraf, 2007.495 (in Russ.).

10. Molzinsky V. V. Problems of studying modern trends in the musical development of youth: abstr. dis. on competition of sci. degree PhD in art history: 17.00.02 / N. A. Rimsky-Korsakov's Leningrad State Conservatory. Leningrad, 1986. 16 (in Russ.). 